Article

\title{
Investigation of E-Core Modular Permanent Magnet Wind Turbine
}

\author{
Aimeng Wang and Shanshan $\mathrm{Li}^{*}$ \\ School of Electrical and Electronic Engineering, North China Electric Power University, Baoding 071003, China; \\ aimeng@ncepu.edu.cn \\ * Correspondence: shanshanli@ncepu.edu.cn
}

Received: 20 March 2020; Accepted: 3 April 2020; Published: 6 April 2020

\begin{abstract}
Under the adverse trend of fossil energy attenuation and air pollution, wind power effectively alleviates the global energy crisis and environmental pollution. For wind turbines, especially large offshore wind turbines, their transportation, installation, and maintenance are very inconvenient. In order to solve this problem, this paper presents an E-core stator modular machine which inserts stator gap into the unwounded teeth of the fractional-slot concentrated winding (FSCW) permanent magnet (PM) machine. The winding factor of the new stator structure machine was derived. The electromagnetic models of 12-slot/10-pole and 12-slot/14-pole modular FSCW PM machines and traditional FSCW PM machines were established using the finite element analysis (FEA) software, and the open-circuit flux density, cogging torque, load torque, loss, and efficiency were simulated and analyzed. The results showed that the modular structure of E-core stator not only simplified the transportation, installation, and maintenance of wind turbines, but also optimized the electromagnetic performance of the 12-slot/14-pole machine, i.e., improved the output torque and operation efficiency.
\end{abstract}

Keywords: wind turbine; stator gap; E-core stator modular; finite element analysis (FEA)

\section{Introduction}

High-performance permanent magnet (PM) synchronous machines have been widely used in renewable energy fields, such as wind power generation, because of its small size, high torque density, and high efficiency [1]. For large-scale wind turbines, because of their huge volume and inconvenience of production, transportation, installation, and maintenance, determining how to simplify the actual production process will be of great significance to energy transformation and the realization of modern energy system. If the stator is modularized in blocks, it can simplify the production, transportation, installation, and maintenance of the machine [2,3]. Besides the modularization of the stator core, stator winding and rotor can also be modularized [4-7]. The coil of concentrated winding is shorter and more efficient than that of distributed winding, which was discovered by Hiroyuki Akita [8]. On this basis, a stator structure which was separated but not completely disconnected at the corresponding stator yoke of each slot was proposed. The slot filling factor and winding efficiency were improved by this stator core. However, due to the influence of manufacturing process, there is an additional gap after installation. Therefore, this structure can be regarded as a modular stator structure. The influence of the additional gaps of the stator yoke on the cogging torque of PM machines was investigated by Z. Q. $\mathrm{Zhu}$ [9]. The results showed that the magnitude of cogging torque was increased. However, research on other performance of modular machine is lacking. Some scholars have purposely made gaps in the stator core to form a real modular structure. For example, the U-core modular structure of the stator is formed by removing part of the yoke [10], as shown in Figure 1b. Although it is beneficial to reduce 
the waste of punching and simplify the machine manufacturing, its strength is difficult to guarantee. Moreover, this modular structure limits the flux path and reduces the output torque.

In order to explore a real modular structure, which is not only convenient for production, transportation, installation, and maintenance, but also has certain strength and can improve the electromagnetic performance of the machine, this paper proposes an E-core modular stator, as shown in the Figure 1a, which inserted the stator gap into the unwounded teeth by cooperating with the single-layer concentrated winding. The models of E-core modular PM machine and traditional integrated PM machine were established using the FEA software. The two machines were available in 12-slot/10-pole and 12-slot/-14 pole configurations. The calculation formula of the winding factor of the modular machine was deduced by the numerical calculation method, and the open-circuit flux, air-gap flux density, cogging torque, load torque, hysteresis loss, eddy current loss, and efficiency were simulated and analyzed. The results showed that the load torque and efficiency were increased after the PM machine with 12-slot/14-pole was modularized. Therefore, compared with the U-core modular stator structure, the modular structure proposed in this paper has better electromagnetic performance and higher strength.

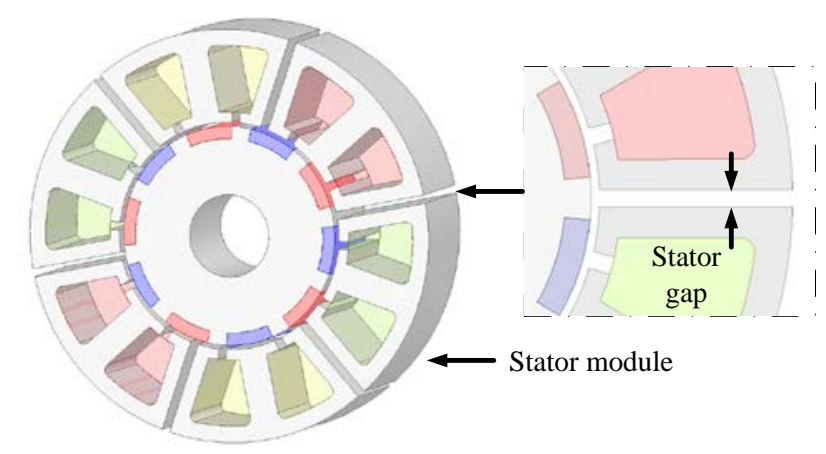

(a)

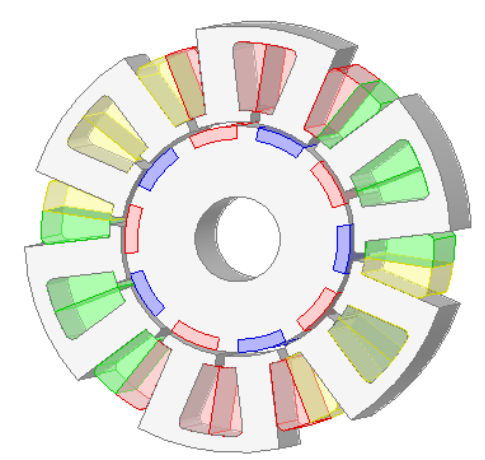

(b)

Figure 1. (a) Structure of "E" core stator modules. (b) Structure of "U" core stator modules.

\section{Structure of "E" Core Stator Modules}

The FSCW refers to the winding with pitch $y=1$. The E-core stator modules proposed in this paper was obtained by inserting the stator gap into the unwounded teeth. Each module contained one coil. The structure diagram of E-core stator module is shown in Figure 1a.

E-core modular stator and single-layer concentrated winding could greatly simplify transportation and installation. Because of its unique modular stator structure and winding form, the phase windings are relatively independent in physical space, which avoids the fault propagation from one phase to another and improves the fault tolerance. Only the fault modules are removed during maintenance. Because of its relatively independent stator structure, the machine can be wound on each stator modules at the same time during manufacture, which shortens the manufacturing cycle, facilitates automatic winding, and improves the filling factor.

In the process of assembly, the nonferromagnetic material or the heat-dissipating pipeline can be filled in the stator gap to improve the fault tolerance and take away the heat that is difficult to dissipate when the machine is running, thereby improving the power density and operating efficiency [11]. The schematic diagram of the cooling pipe in the stator gap is shown in Figure 2. The stator gaps were separated from the air gap by an iron sheet to ensure that no coolant flowed into the air gap to cause short circuit. Figure 2a shows the axial cooling diagram, which was composed of a parallel inlet pipe and outlet pipe. Since the 12-slot stator modular machine had six stator gaps, there were six inlets and six outlets in total. The radial cooling diagram is shown in Figure 2b. It can be seen that compared with the traditional cooling method of one circle of cooling pipe around the stator, the E-core modular machine can make the coolant flow into the stator gaps, significantly increasing 
the cooling area. Therefore, the "E" core stator modular machine has application prospects for large offshore wind turbines.

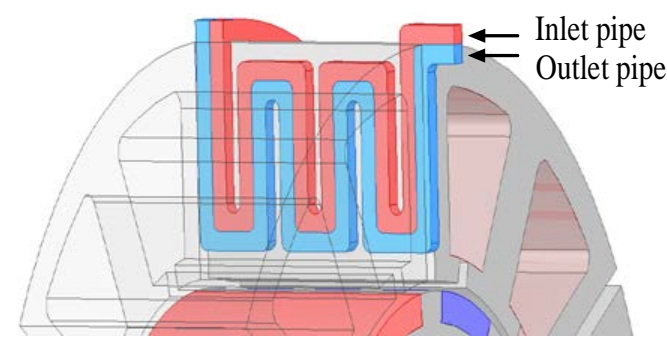

(a)

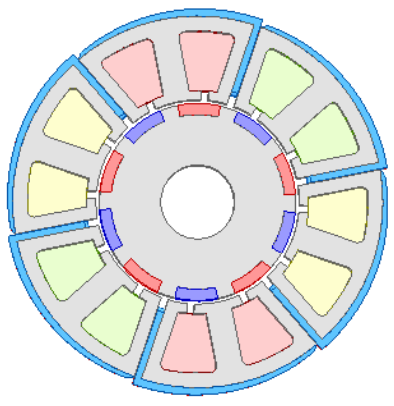

(b)

Figure 2. (a) Axial cooling using the stator gaps. (b) Radial cooling using the stator gaps.

\section{Finite Element Model of the Four Machines}

The finite element models of two stator structure (E-core stator and integral stator) machines are shown in Figure 3. A laminated core was adopted for stator and rotor. For the integral stator machines, shown in Figure $3 \mathrm{a}, \mathrm{c}$, both wound and unwound teeth had a width of $2 \mathrm{t}_{0}$. For the E-core stator machines, the stator gap $W_{0}$ between two stator modules was inserted in the unwound teeth, making the width of the unwound teeth $2 t_{0}+W_{0}$, as shown in Figure $3 b, d$. As a result, the area of modular stator slots was smaller than that of integrated stator slots. When the filling factor and the number of coil turns were constant, the copper loss increased due to the decrease of wire diameter. In addition, a series connection was adopted for each phase winding. At the same time, in order to eliminate the influence of the tooth tip width on the performance, all machines had the same tooth tip with a width of $t_{\text {tip }}$ on both wound and unwound teeth, making the machines of different stator structures have the same slot opening width. It should be noted that, for E-core stator machine, the tip width of unwound teeth included the length of stator gap $W_{0}$.

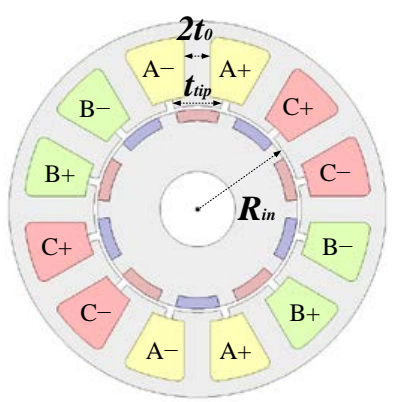

(a)

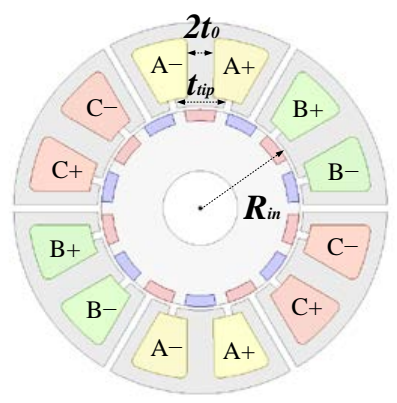

(c)

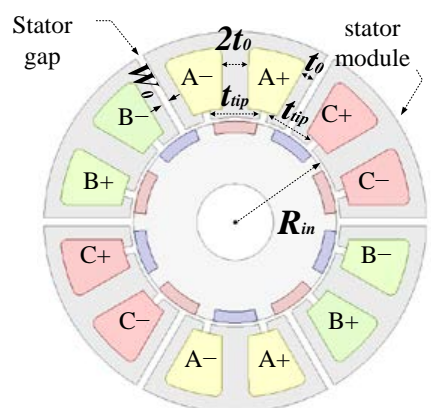

(b)

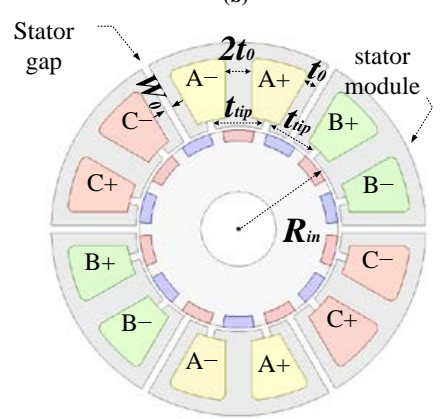

(d)

Figure 3. Finite element model of the four machines. (a) 12s/10p integral machine; (b) 12s/10p E-core modular machine; (c) 12s/14p integral machine; (d) 12s/14p E-core modular machine. 
Since the machines involved in the paper are all single-layer concentrated windings, each slot contains only one coil side, and $2 \mathrm{n}$ slots contains $\mathrm{n}$ coils, the number of slots in the machine should be even. The machines in this paper are all three-phase permanent magnet machines. Therefore, the number of coils in the stator should be a multiple of three. For fractional-slot single-layer concentrated winding machines, the number of coils contained in each phase should be even to avoid an unbalanced magnetic force (UMF) $[12,13]$. An unbalanced magnetic force can cause mechanical vibration and noise and damage to machine bearings, and when its frequency is consistent with the system's, it will cause resonation and harm the normal operation of the machines. The above relationships can be summarized as follows:

$$
\begin{gathered}
N_{c}=\frac{1}{2} \\
N_{S} N_{c}=3 \times 2 \mathrm{~N}
\end{gathered}
$$

where $N_{s}$ is the number of slots, $N_{c}$ is the number of coils per slot, and $N$ is any positive integer.

Therefore, for a single-layer FSCW machine with only one coil side per slot, the number of stator slots should be at least 12 . The design parameters of the established machine model are shown in Table 1.

It is worth noting that, as mentioned before, the use of modularization can increase the filling factor, thus reducing the current density. In the case of the same current density, the modular machine can increase the power density of the machine by increasing the current. However, in order to ensure that the electromagnetic effects of the modular structure are studied under the same rated parameters of the models, the same current was applied to the four models. Therefore, the influence of filling factor on electromagnetic performance was ignored, and the same filling factor was adopted for the four machines.

Table 1. Design parameters of the investigated machines.

\begin{tabular}{cccc}
\hline Parameter & Value & Parameter & Value \\
\hline Rated output power $(\mathrm{W})$ & 230 & Stator gap width $\mathrm{W}_{0}(\mathrm{~mm})$ & 2 \\
Rated speed $(\mathrm{rpm})$ & 400 & Winding pitch & 1 \\
Rated torque $(\mathrm{Nm})$ & 5.5 & Slot opening $(\mathrm{mm})$ & 2 \\
Slots & 12 & Stack length $(\mathrm{mm})$ & 50 \\
Poles & $10 / 14$ & Air-gap length $(\mathrm{mm})$ & 1 \\
Stator outer diameter $(\mathrm{mm})$ & 100 & Tooth body width $2 \mathrm{t}_{0}(\mathrm{~mm})$ & 7 \\
Stator inner diameter $(\mathrm{mm})$ & 55 & Tooth tip width $\mathrm{t}_{\text {tip }}(\mathrm{mm})$ & 13 \\
Stator yoke height $(\mathrm{mm})$ & 4 & Magnet thickness $(\mathrm{mm})$ & 3 \\
Rotor outer diameter $(\mathrm{mm})$ & 53 & Magnet remanence $(\mathrm{T})$ & 1.23 \\
Rotor inner diameter $(\mathrm{mm})$ & 20 & Filling factor $\mathrm{k}_{\mathrm{b}}$ & 0.75 \\
\hline
\end{tabular}

\section{Electromagnetic Performance of "E" Core Modular PM Machine}

\subsection{Winding Factor}

For modular stator machines shown in Figure $3 b, d$, since the existence of stator gaps $W_{0}$ did not affect the relative position of each phase coil in the stator and the electromotive force directions of adjacent coils of each phase were the same, the modular stator machine had the same distribution factor as integral stator counterpart.

$$
k_{d}=k_{d}^{\prime}=1
$$

where $k_{d}$ and $k_{d}^{\prime}$ are the distribution factor of integral stator and modular stator machines, respectively. 
However, the pitch factor of integrated machine and modular machine was different due to the change of slot pitch. For traditional equal tooth integral stator machines shown as Figure $3 a, c$, the pitch factor $k_{p}$ and winding factor $k_{w}$ can be calculated by the following formula:

$$
\begin{gathered}
k_{p}=\sin \cdot n\left(\frac{y}{\tau} \cdot \frac{\pi}{2}\right) \\
k_{w}=k_{p} \cdot k_{d}
\end{gathered}
$$

where $n$ is the harmonic order, $\tau=2 \pi / 2 p$ is the pole pitch, and $y=2 \pi / N_{s}$ is the slot pitch.

Figure 4 shows the stator structure of the modular stator machine. It can be seen that the slot pitch of the modular stator machine was reduced compared to the integral stator machine due to the existence of the stator gaps, which can be calculated by:

$$
\begin{gathered}
\frac{\alpha_{0}}{2}=\arcsin \left(\frac{W_{0}}{2 R_{\text {in }}}\right) \\
2 y_{\text {New }}=2 y-\alpha_{0}
\end{gathered}
$$

According to Equations (6) and (7), the slot pitch of modular machine is

$$
y_{\text {New }}=y-\arcsin \left(\frac{W_{0}}{2 R_{\text {in }}}\right)
$$

Therefore, the pitch factor $k_{p}^{\prime}$ and winding factor $k_{w}^{\prime}$ of modular machine were calculated by the following formula:

$$
\begin{gathered}
k_{p}^{\prime}=\sin \cdot n\left(\frac{y_{N e w}}{\tau} \cdot \frac{\pi}{2}\right) \\
k_{w}^{\prime}=k_{p}^{\prime} \cdot k_{d}^{\prime}
\end{gathered}
$$

The winding factors of the four machines calculated by Equations (3)-(10) are shown in Table 2. For 12-slot/10-pole machines, since the slot pitch was smaller than the pole pitch and the existence of the stator gap further reduced the slot pitch, therefore, the pitch factor of the modular stator machine was reduced compared to the integral stator counterpart. For the 12-slot/14-pole machines, because the slot pitch was greater than the pole pitch, although the existence of the stator gap reduced the slot pitch of the machine, the ratio of the slot pitch to the pole pitch $y_{\text {New }} / \tau$ was increased, thereby increasing the pitch factor of the modular stator machine.

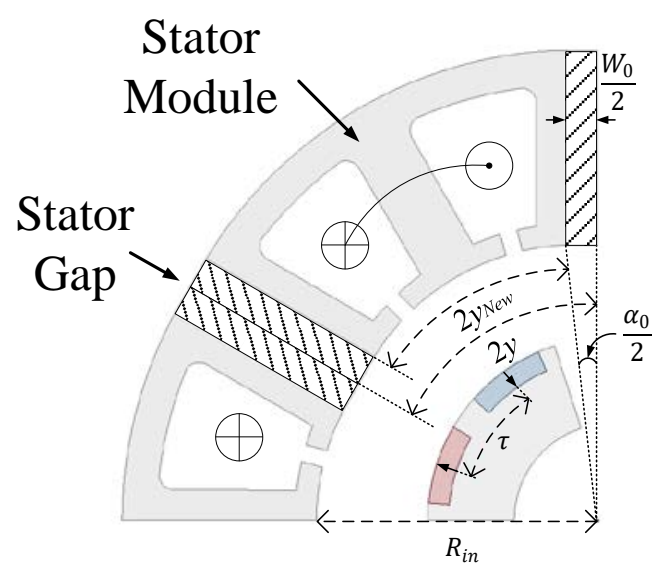

Figure 4. E-core modular stator structure (nonactual proportion). 
Table 2. Winding factor comparison.

\begin{tabular}{ccccc}
\hline \multirow{2}{*}{$\begin{array}{c}\text { Harmonic } \\
\text { Orders }\end{array}$} & \multicolumn{2}{c}{ 12-slot/10-pole } & \multicolumn{2}{c}{ 12-slot/14-pole } \\
\cline { 2 - 5 } & Integral & Modular & Integral & Modular \\
\hline $\mathrm{n}=1$ & 0.966 & 0.938 & 0.966 & 0.991 \\
$\mathrm{n}=3$ & 0.707 & 0.490 & 0.707 & 0.919 \\
$\mathrm{n}=5$ & 0.259 & 0.192 & 0.259 & 0.782 \\
$\mathrm{n}=7$ & 0.259 & 0.782 & 0.259 & 0.587 \\
\hline
\end{tabular}

\subsection{Open-Circuit Flux Characteristics}

\subsubsection{Open-Circuit Air-gap Flux Density}

For modular stator machines, the existence of stator gaps changed the air gap permeability of the machine and the magnetic path in the stator core, causing the air-gap flux density to change, as shown in Figure 5. For modular stator machines, the air-gap flux density was reduced relative to integral stator machines regardless of the number of rotor poles. This was because, for modular stator machines, the existence of the stator gap increased the width of the effective slot opening (stator gap + slot opening), as shown in Figure 4, which, in turn, reduced the stator iron section surface facing the air gap.

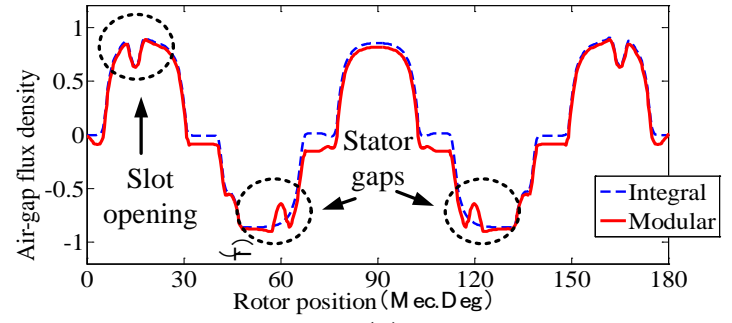

(a)

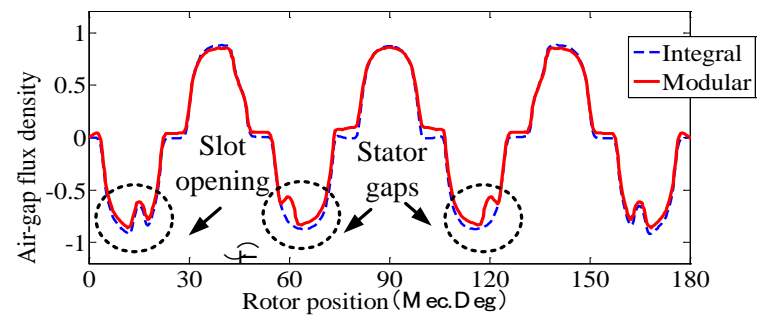

(b)

Figure 5. Open-circuit air-gap flux densities. (a) 12s/10p; (b) 12s/14p.

\subsubsection{Open-Circuit Flux Density}

The flux density distribution can directly reflect the field saturation of the machine to verify the rationality of the designed PM machine. Using the FEA software ANSYS Maxwell 2D to calculate the magnetic density of the teeth and yoke of the 12-slot/10-pole and 12-slot/14-pole machines under open-circuit state, it was found that the magnetic density of the stator teeth and yoke was between 1.6 $\mathrm{T}$ and $1.81 \mathrm{~T}$, and the distribution was reasonable, as shown in Figure 6.

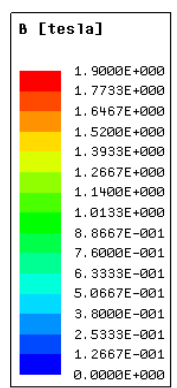

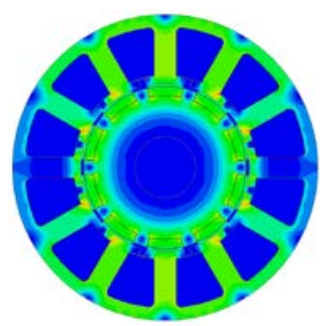

(a)

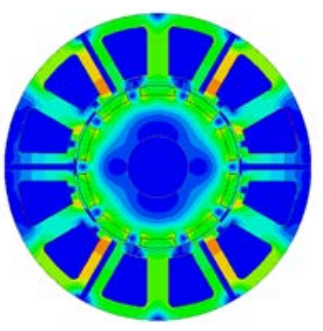

(b)

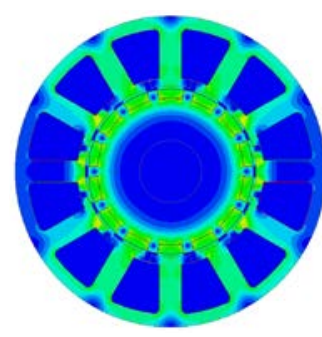

(c)

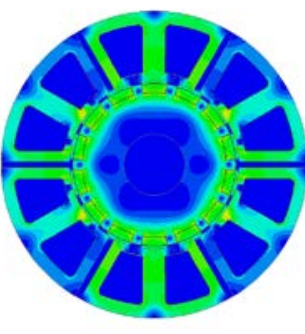

(d)

Figure 6. Flux density distribution of the four machines. (a) 12s/10p integral machine; (b) 12s/10p E-core modular machine; (c) 12s/14p integral machine; (d) 12s/14p E-core modular machine. 


\subsubsection{Open-Circuit Flux Distribution}

In order to observe the flux trend more specifically, the open-circuit flux distribution of the four machines was simulated, as shown in Figure 7. The rotor was at the position where the A-phase flux was maximized, i.e., the magnetic pole axis coincided with the tooth center.

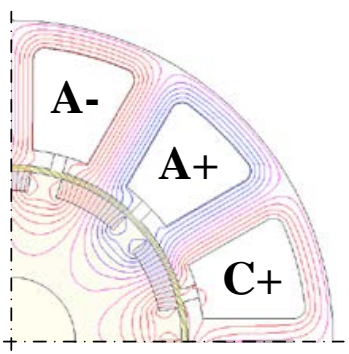

(a)

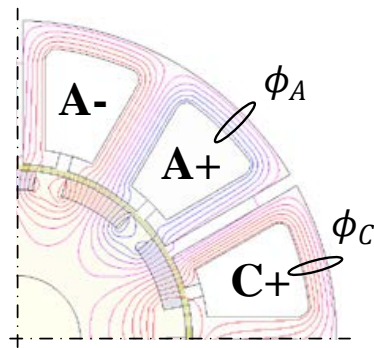

(b)

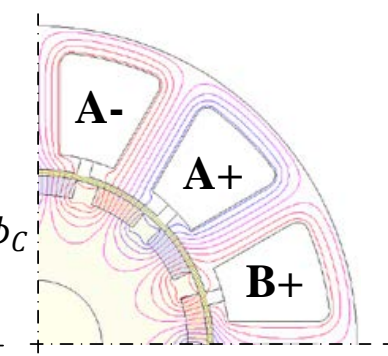

(c)

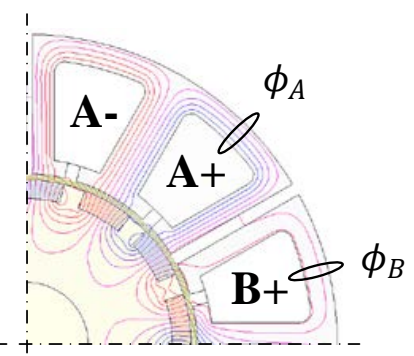

(d)

Figure 7. Flux distribution of the four machines. (a) 12s/10p integral machine; (b) 12s/10p E-core modular machine; (c) 12s/14p integral machine; (d) 12s/14p E-core modular machine.

It can be seen from Figure 7 that the stator gap of 12-slot/10-pole modular machine made it difficult for the flux of other phases to enter phase A because the flux needed to pass through the stator gap first, and the permeability of air was far lower than that of ferromagnetic materials. This directly resulted in the decrease of the A-phase flux of the 12-slot/10-pole modular machine compared with the integrated machine, and the slight increase of the C-phase flux, which as the defocusing effect, as shown in Figure 7a,b. On the contrary, for the 12-slot/14-pole modular machine, by comparing the flux distribution of the integrated machine, it can be seen that the stator gap prevented the flux of phase A from dispersing into other phases, which made the A-phase flux of the 12-slot/14-pole modular machine increase compared with the integrated machine, while the B-phase flux decreased, which was the focusing effect, as shown in Figure 7c,d.

\subsubsection{Open-Circuit Flux Linkage}

The open-circuit flux waveform of each phase of the four machines is shown in Figure 8. It can be seen that under different slot pole configurations, the amplitude of each phase flux waveform of the machine changed with the different stator structure. This was mainly because, on the premise of the same width of the stator tip, the amplitude of the flux waveform of each phase was mainly affected by three factors: Winding factor, open-circuit air gap magnetic density, and the effect of focusing/defocusing. For the 12-slot/10-pole modular machine, compared with the integrated machine, the flux amplitude of each phase was reduced. This was because, due to the existence of stator gap, the 12-slot/10-pole modular machine had a smaller winding factor, smaller open-circuit air-gap flux density (Figure 5), and defocusing effect (Figure 7b). Although the stator gap of 12-slot/14-pole machine made the magnitude of open-circuit air-gap flux density decrease, under the combined effect of higher winding factor and focusing effect (Figure 7d), the magnitude of open-circuit flux of modular machine was higher than that of integrated machine. 


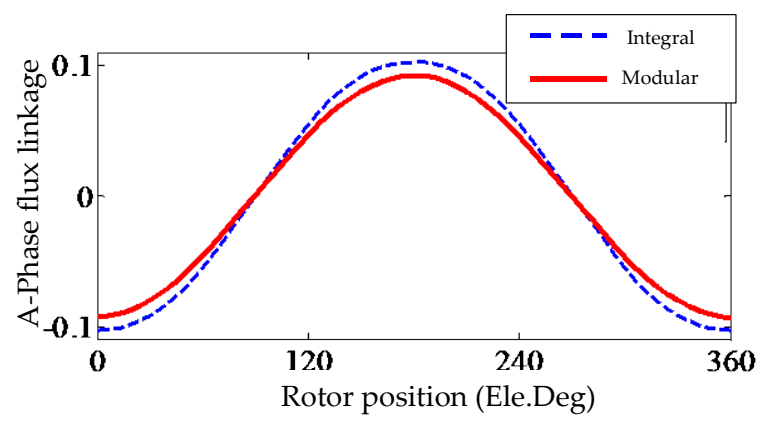

(a)

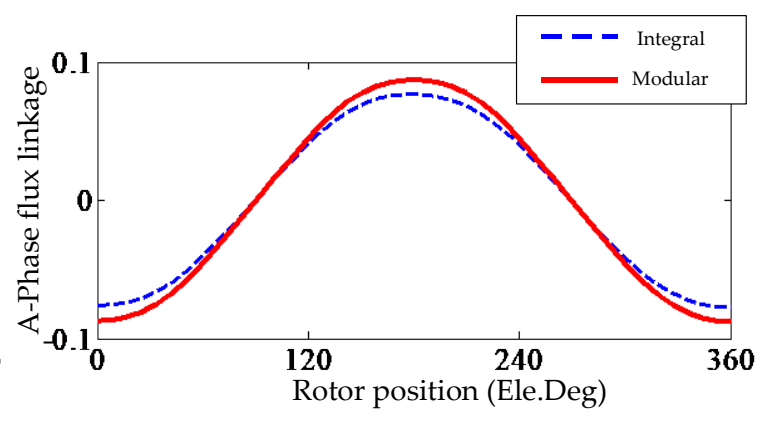

(b)

Figure 8. Open-circuit flux linkage. (a) 12s/10p; (b) 12s/14p.

\subsection{Torque Characteristics}

\subsubsection{On-Load and Reluctance Torque}

The on-load torque and reluctance torque waveforms of the four machines are shown in Figure 9. When the reluctance torque reached the maximum value, it can be seen that the current angle was not the same as the current angle of the on-load torque, and the current angle of the reluctance torque was greater than the on-load torque. For the 12-slot/10-pole machines, the on-load and reluctance torque of the modular stator machine were lower than that of the integral stator machine. For the 12-slot/14-pole machines, the stator modules increased the on-load torque and reluctance torque, making it more excellent in the flux-weakening operation.

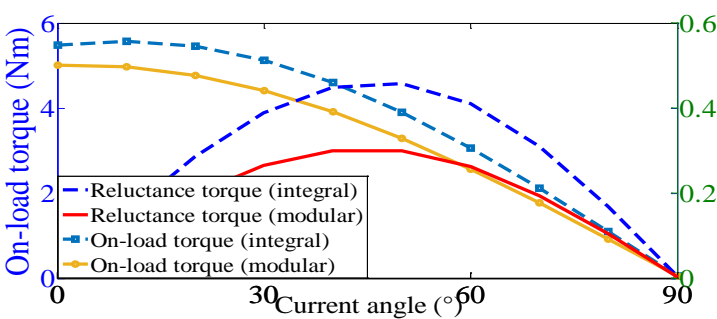

(a)

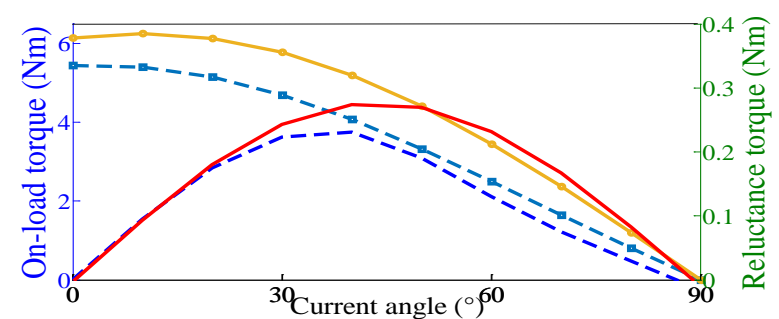

(b)

Figure 9. Reluctance and on-load torque versus current angles. (a) 12s/10p; (b) 12s/14p.

\subsubsection{Cogging Torque}

The cogging torque waveforms of the four machines are shown in Figure 10. It can be seen that, regardless of the stator structure, the cogging torque of the 12-slot/10-pole machine was generally larger than that of the 12-slot/14-pole counterpart. For the integral stator motor, when the rotor turned one circle, the period of fundamental cogging torque was equal to the least common multiple of the number of slots and poles. However, due to the change of stator symmetry caused by stator gap, the period of fundamental cogging torque of modular motor was equal to the least common multiple of the number of stator gaps and poles. Therefore, the period of fundamental cogging torque of 12-slot/10-pole machine was less than that of 12-slot/14-pole machine, regardless of the stator structure. In general, when the other conditions are the same, the smaller the period of fundamental cogging torque in the fractional-slot machine, the greater the magnitude of cogging torque [14]. At the same time, it can be seen from Figure 10 that for the two kinds of stator structure machines, the maximum of the cogging torque of the modular stator machine was higher than that of the integral stator counterpart due to the existence of the stator gap. Therefore, the modular stator machines have a higher torque ripple than the integral stator counterparts. 

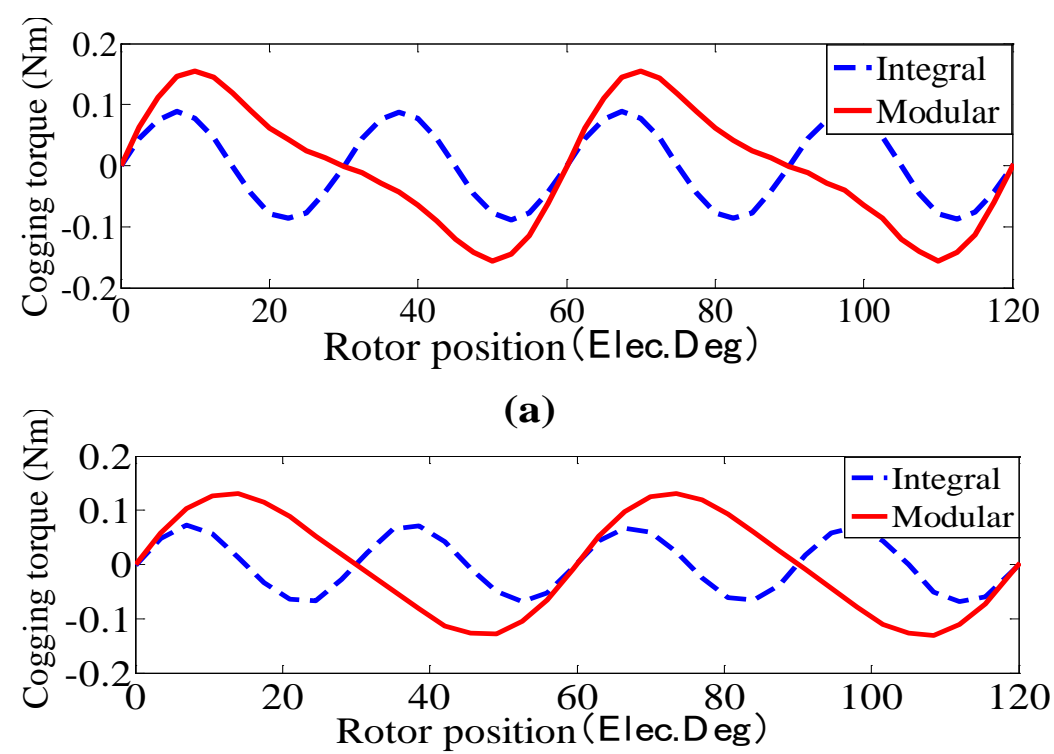

(b)

Figure 10. Cogging torques versus rotor. (a) 12s/10p; (b) 12s/14p.

The harmonic analysis of the cogging torque waveform of four machines are shown in Figure 11, it can be seen that the cogging torque waveform of the four machines contains 12 harmonic components regardless of the slot/pole configuration, this is because for both machines, the number of slots is 12 and the slot opening width remains the same $(2 \mathrm{~mm})$, therefore, the cogging torque waveform has 12 periods in the $360^{\circ}$ electrical angle.

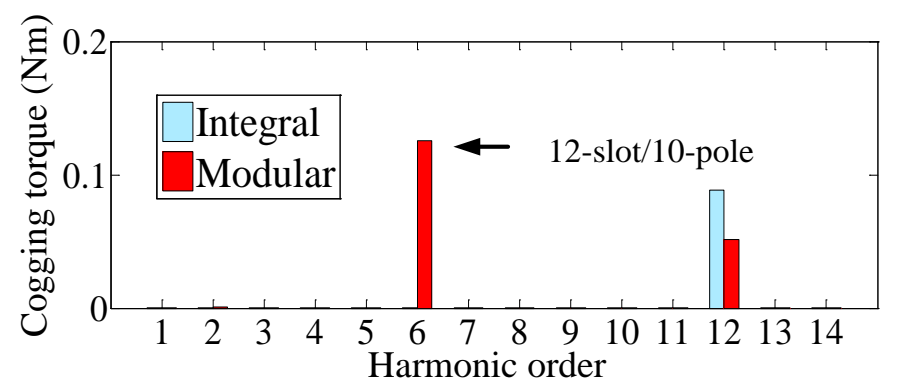

(a)

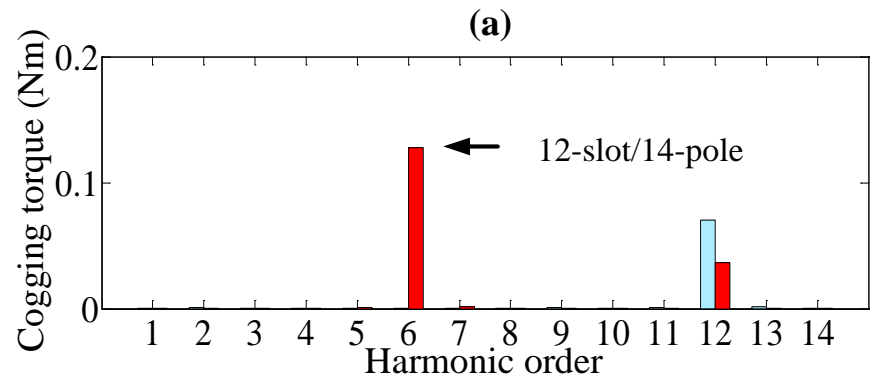

(b)

Figure 11. Cogging torques harmonics. (a) 12s/10p; (b) 12s/14p.

It can also be seen from Figure 11 that, for modular stator machines, the cogging torque waveform had a harmonic component of 12 th and 6th, regardless of the slot/pole configuration. This was because, for modular stator machines, due to its independent stator modules, the machine had 6 stator gaps in addition to 12 slot openings in the inner circle of the stator. This introduced the sixth harmonic component into the cogging torque waveform of the modular stator machine, and the amplitude of 
the sixth harmonic component increased as the stator gap width increased. This also explains the phenomenon in Figure 10, in which the modular stator machine cogging torque was greater than the integral stator counterpart.

\subsection{Loss Characteristics}

\subsubsection{Iron Losses}

As we know, iron loss includes hysteresis loss and eddy current loss. The silicon steel sheets were very thin, so the eddy current losses were very low. Therefore, only the hysteresis loss of the stator core and the eddy current loss of PM were considered. The calculation formula of hysteresis loss is:

$$
P_{h}=k_{h} f\left(B_{m}\right)^{2}
$$

where $P_{h}$ is the hysteresis loss, $k_{h}$ is the hysteresis core loss coefficient, $f$ is the electrical frequency, and $B_{m}$ is the maximum flux density.

In this paper, we used D23_50 stator lamination, and the $k_{h}=309$. The hysteresis curve is shown in Figure 12.

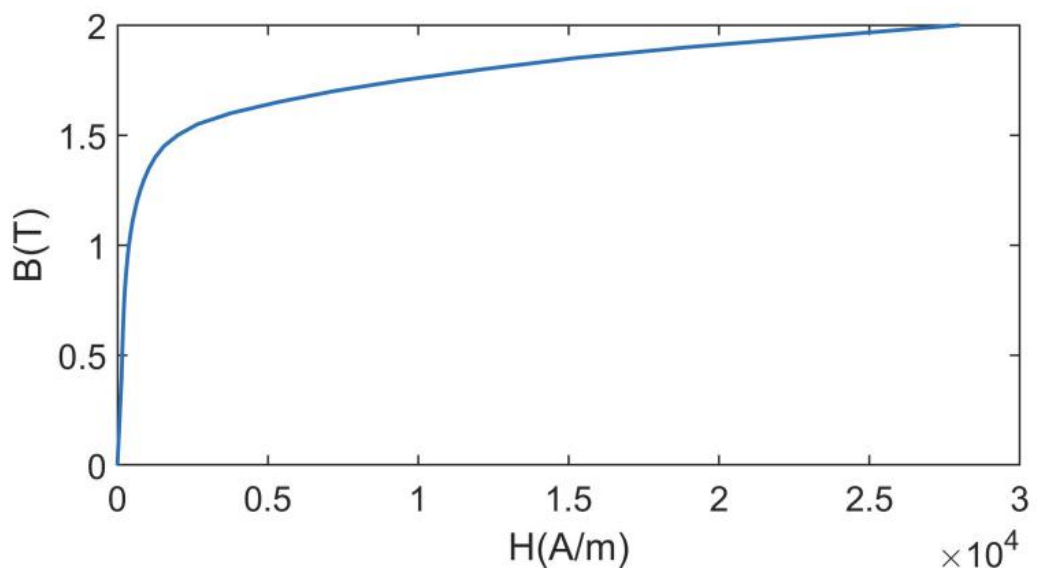

Figure 12. Hysteresis curve of the iron core.

At the rated speed, the hysteresis loss waveform of the stator core of the four machines are shown in Figure 13a,c. It can be seen that under open-circuit conditions, the hysteresis loss of the stator core of the modular stator machine was increased compared to the integral stator counterpart. This was because, for modular stator machines, the existence of the stator gap increased the flux density of the unwound teeth. The excessive teeth flux density caused high hysteresis loss at the stator core, so the no-load hysteresis loss of the modular stator machine was higher than that of the integral stator counterpart.

At the rated speed, the eddy current loss waveform of the permanent magnets of the four machines are shown in Figure 13b,d. It can be seen from the figure that under no-load conditions, the eddy current loss of the modular stator machine was increased compared to the integral stator counterpart. This was because, for the modular stator machines, due to the existence of the stator gap, the open-circuit air gap flux density waveform was distorted and the amplitude of each harmonic was increased, as shown in Figure 5. The increased part of the harmonics acted on the permanent magnets, causing additional permanent magnet eddy current losses. Therefore, the no-load eddy current loss at the permanent magnet of the modular stator machine was higher than that of the integral stator counterpart. 


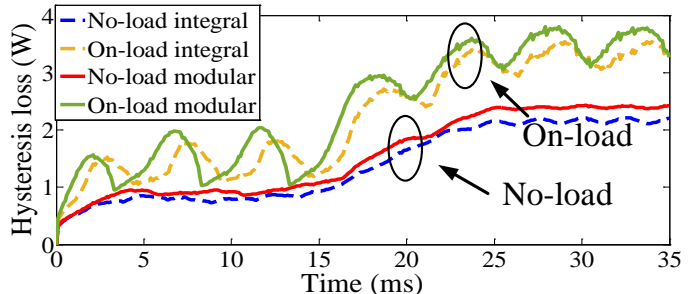

(a)

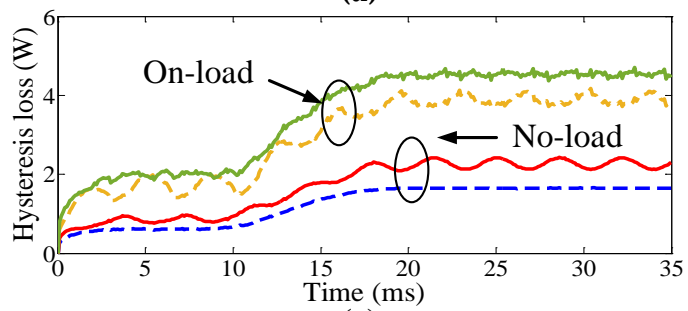

(c)

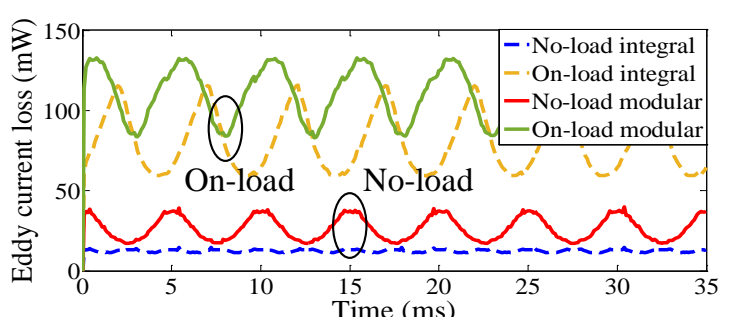

(b)

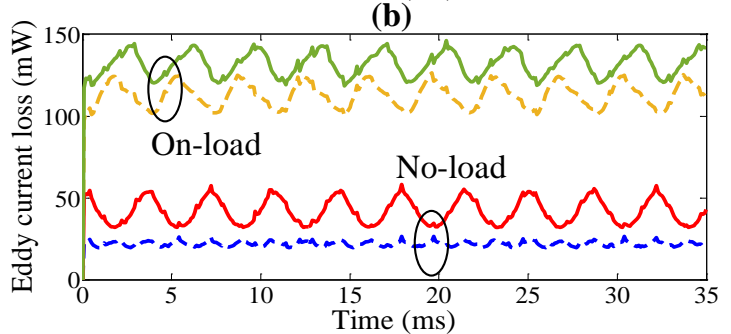

(d)

Figure 13. Iron losses in the four machines. (a) 12s/10p; (b) 12s/10p; (c) 12s/14p; (d) $12 \mathrm{~s} / 14 \mathrm{p}$.

\subsubsection{Copper Losses and Efficiency}

At rated conditions, the winding copper loss of the machine is as follows:

$$
P_{C u}=N_{s} N_{c}^{2} \rho \frac{L_{e f}}{S \cdot k_{b}} I_{R M S}^{2}
$$

where $\rho$ is the copper wire resistivity $(\Omega \cdot \mathrm{m}), L_{e f}$ is the machine axial length $(\mathrm{m}), S$ is the cross-sectional area per slot $\left(\mathrm{m}^{2}\right), k_{b}$ is the filling factor, and $I_{R M S}$ is the rated $R M S$ phase current (A).

It can be seen from Equation (12) that the difference in the slot/pole configuration did not affect the copper loss of machines, and the existence of the stator gap inevitably squeezed the size of the stator slots, so that the cross-sectional area $\mathrm{S}$ of each slot of the modular stator was reduced compared with the integral stator machine, thereby increasing the winding copper loss during the rated operation.

At rated conditions, the efficiency of the machine is as follows:

$$
\begin{aligned}
\eta & =\frac{P_{\text {out }}}{P_{\text {out }}+P_{\text {Loss. }}} \times 100 \% \\
& =\frac{T_{\text {avg }} \cdot \omega}{T_{\text {avg }} \cdot \omega+P_{C u}+P_{F e}}
\end{aligned}
$$

where $P_{\text {out }}$ is the output power $(\mathrm{W}), P_{\text {Loss }}$ is the loss power $(\mathrm{W}), T_{\text {avg }}$ is the average load torque $(\mathrm{N} \cdot \mathrm{m})$, $\omega$ is the rated angular velocity $(\mathrm{rad} / \mathrm{s}), P_{C u}$ is the copper loss $(\mathrm{W})$, and $P_{F e}$ is the iron loss $(\mathrm{W})$.

From the results of the average torque, load iron loss and copper loss of machines in the previous section, the operating efficiency of each machine under rated conditions can be calculated. The results are shown in Table 3. As can be seen, for the 12-slot/10-pole, the operating efficiency of modular stator machine was reduced compared to the integral stator machine. This was because the modular stator caused greater iron and copper losses. For the 12-slot/14-pole, the operating efficiency of the modular stator machine was slightly increased compared to the integral stator machine because although the modular stator machine had greater iron and copper losses, the increase in output torque due to the existence of stator gap (Figure 9) offset the effect of loss on efficiency.

Table 3. Efficiency comparison of modular and integral machines.

\begin{tabular}{ccc}
\hline Efficiency & 12-slot/10-pole & 12-slot/14-pole \\
\hline Integral stator & $86.8 \%$ & $86.6 \%$ \\
E-core modular stator & $84.5 \%$ & $86.9 \%$ \\
\hline
\end{tabular}




\subsection{Summary}

After the modular stator transformation of the 12s/10p and 12s/14p PM machine, its performance was compared with the original integrated machine, as shown in the Table 4. Hollow arrows represent performance optimization. The modularization of the 12-slot/14-pole machine improved the winding factor, flux linkage of each phase, reluctance torque, output torque, and efficiency. However, the performance of the 12-slot/10-pole machine was reduced after modularization. Therefore, the 12-slot/14-pole machine was more suitable for stator transformation.

Table 4. Comparisons of performance with the modular structure.

\begin{tabular}{ccc}
\hline Performance & 12-slot/10-pole & 12-slot/14-pole \\
\hline Distribution factor & - & - \\
\hline Pitch factor & $\downarrow$ & $\uparrow$ \\
\hline Flux linkage & $\downarrow$ & $\uparrow$ \\
\hline Reluctance torque & $\downarrow$ & $\uparrow$ \\
\hline Cogging torque & $\uparrow$ & $\uparrow$ \\
\hline Output torque & $\downarrow$ & $\uparrow$ \\
\hline Loss & $\uparrow$ & $\uparrow$ \\
\hline Efficiency & $\downarrow$ & $\uparrow$
\end{tabular}

\section{Discussion}

In this paper, the stator gap was inserted into the unwounded teeth to complete the stator transformation of the integral stator machine, as seen in Table 4:

1. The E-core modular structure changed the pitch factor but kept the distribution factor unchanged. For the $12 \mathrm{~s} / 10 \mathrm{p}$ machine, the pitch factor decreased, while for the $12 \mathrm{~s} / 14 \mathrm{p}$ machine, the pitch factor increased. This was different from the previous modular structure. The modularity obtained by separating the stator yoke did not change the pitch factor and distribution factor because it did not change the area of the slot. However, for U-core modularization, the pitch factor and distribution factor changed due to the existence of stator gap [10].

2. The E-core modular structure reduced the air-gap flux density of the PM machine and increased the cogging torque, regardless of the slot/pole configuration. This was the same as the U-core modularization and the modularization, which separated the stator yoke. However, for the $12 \mathrm{~s} / 14 \mathrm{p}$ E-core modular machine, the flux amplitude of each phase was increased, while for the $12 \mathrm{~s} / 10 \mathrm{p}$ machine, the opposite was true.

3. The E-core modular structure changed the reluctance torque, output torque, and efficiency of the PM machine. The reluctance torque, output torque, and efficiency of the 12s/10p machine were reduced, but for the $12 \mathrm{~s} / 14 \mathrm{p}$ machine, were improved. For the U-core modularization, the output torque was reduced, and the torque ripple was increased [10]. There have been few researches on the other performance of U-core modularization.

In this paper, embedded rotor structures were used. However, the results obtained in this paper are equally applicable to SPM and IPM machines, as well as fractional-slot concentrated winding machines in other slot/pole configurations. Future research can consider how to reduce the cogging torque and losses of E-core modular machine. In addition, the difference of the fixed way between the stator modules also makes the electromagnetic performance of the modular machine different. Whether the modules can be tightly connected has a great influence on the cogging torque, which is also the focus of future research. 


\section{Conclusions}

For large offshore wind turbines, the stator modular transformation will facilitate the transportation of the machine and simplify the installation process of the machine. Combined with single-layer concentrated winding, the fault-tolerant ability of the machine was improved, and the automatic winding was convenient. Moreover, multiple modules can be wound at the same time, which improved the filling factor and shortens the manufacturing cycle. Compared with the integrated machine, in the appropriate slot-pole configuration (when the winding factor was the largest and the pole number was greater than the slot number), the use of E-core modular structure improved the reluctance torque, output torque, and efficiency of the machine. Because the stator gaps can also be equipped with cooling device, the cooling area was larger than the integrated machine, further improving the operation efficiency of the machine. The strength and output torque of the modular structure proposed in this paper is better than U-core modular structures. In addition, for space limited new energy electric vehicles, E-core modularization can also be used to improve the power density of the machine.

At present, the wind power system is developing in the direction of single machine capacity large scale oriented and small-scale supplemented. E-core modularization will have certain practical application value for it.

Author Contributions: Conceptualization, A.W. and S.L.; methodology, A.W.; software, S.L.; validation, S.L.; formal analysis, A.W.; writing—original draft preparation, S.L.; writing—review and editing, A.W. and S.L. All authors have read and agree to the published version of the manuscript.

Funding: This research was funded by Beijing Natural Science Foundation (China) and Natural Science Foundation of Hebei Province (China), grant number 3172037 and E2017502025.

Conflicts of Interest: The authors declare no conflict of interest.

\section{References}

1. Li, G.; Zhu, Z.; Foster, M.P.; Stone, D.A.; Zhan, H. Modular permanent-magnet machines with alternate teeth having tooth tips. IEEE Trans. Ind. Electron. 2015, 62, 6120-6130. [CrossRef]

2. Shen, K.; Xie, B.; Cai, X. Design and research of modular permanent-magnet DC generator based on magnetic integrated transformer for offshore wind farms. J. Eng. 2017, 2017, 2368-2373. [CrossRef]

3. Hosseini, S.; Moghani, J.S.; Ershad, N.F.; Jensen, B.B. Design, prototyping, and analysis of a novel modular permanent-magnet transverse flux disk generator. IEEE Trans. Magn. 2010, 47, 772-780. [CrossRef]

4. Cox, T.; Eastham, F.; Proverbs, J. End turn leakage reactance of concentrated modular winding stators. IEEE Trans. Magn. 2008, 44, 4057-4061. [CrossRef]

5. Wrobel, R.; Mellor, P.H.; McNeill, N.; Staton, D.A. Thermal performance of an open-slot modular-wound machine with external rotor. IEEE Trans. Energy Convers. 2010, 25, 403-411. [CrossRef]

6. Rahman, L.U.; Khan, F.; Fatima, A.; Khan, M.A. Novel modular rotor single phase wound field flux switching machine. In Proceedings of the 2018 International Conference on Power Generation Systems and Renewable Energy Technologies (PGSRET), Islamabad, Pakistan, 10-12 September 2018; pp. 1-5.

7. Thomas, A.S.; Zhu, Z.Q.; Wu, L.J. Novel modular-rotor switched-flux permanent magnet machines. IEEE Trans. Ind. Appl. 2012, 48, 2249-2258. [CrossRef]

8. Akita, H.; Nakahara, Y.; Miyake, N.; Oikawa, T. New core structure and manufacturing method for high efficiency of permanent magnet motors. In Proceedings of the 38th IAS Annual Meeting on Conference Record of the Industry Applications Conference, Salt Lake City, UT, USA, 12-16 October 2003; Volume 1, pp. 367-372.

9. Zhu, Z.Q.; Azar, Z.; Ombach, G. Influence of additional air gaps between stator segments on cogging torque of permanent-magnet machines having modular stators. IEEE Trans. Magn. 2012, 48, 2049-2055. [CrossRef]

10. Heins, G.; Ionel, D.M.; Thiele, M. Winding factors and magnetic fields in permanent-magnet brushless machines with concentrated windings and modular stator cores. IEEE Trans. Ind. Appl. 2015, 51, 2924-2932. [CrossRef]

11. Bianchi, N.; Bolognani, S.; Pre, M.D.; Grezzani, G. Design considerations for fractional-slot winding configurations of synchronous machines. IEEE Trans. Ind. Appl. 2006, 42, 997-1006. [CrossRef] 
12. Nollau, A.; Gerling, D. Novel cooling methods using flux-barriers. In Proceedings of the 2014 International Conference on Electrical Machines (ICEM), Berlin, Germany, 2-5 September 2014; pp. 1328-1333.

13. Barcaro, M.; Bianchi, N.; Magnussen, F. Faulty operations of a PM fractional-slot machine with a dual three-phase winding. IEEE Trans. Ind. Electron. 2011, 58, 3825-3832. [CrossRef]

14. Dajaku, G.; Gerling, D. Analysis of different PM machines with concentrated windings and flux barriers in stator core. In Proceedings of the 2014 International Conference on Electrical Machines (ICEM), Berlin, Germany, 2-5 September 2014; pp. 375-384.

(C) 2020 by the authors. Licensee MDPI, Basel, Switzerland. This article is an open access article distributed under the terms and conditions of the Creative Commons Attribution (CC BY) license (http://creativecommons.org/licenses/by/4.0/). 